\title{
Implicit memory for phonological processes in visual stem completion
}

\author{
JAY G. RUECKL \\ University of Connecticut, Storrs, Connecticut \\ and Haskins Laboratories, New Haven, Connecticut \\ and \\ SHASHI MATHEW \\ Harvard University, Cambridge, Massachusetts
}

\begin{abstract}
Four experiments were conducted investigating the role of phonology in repetition priming. Experiment 1 used a cross-modal priming paradigm in which participants made semantic judgments about spoken words and then performed a visual stem completion task. In Experiments 2-4, both the primes and the test stems were presented visually. The results of the first three experiments revealed that priming transfers across interpretations of a homophone. That is, seeing or hearing week primes both week and weak. The results of Experiment 4 showed that homophone priming cannot be attributed to the orthographic similarity of homophonic words. Together, these results indicate that repetition priming on a visual word completion task includes a phonological component.
\end{abstract}

Although the identification of a written word may appear to be a relatively simple act, it is in fact a rather remarkable accomplishment. Indeed, research by several generations of psychologists has revealed that visual word identification reflects the interplay of a variety of psychological processes (see review by Henderson, 1982). For example, a variety of findings (reviewed below) indicate that phonological processes play an early and influential role in the identification process. Similarly, a substantial body of evidence shows that word identification is influenced (often in rather subtle ways) by the memory of recent processing episodes.

The question we address here involves the relationship between these two aspects of the word identification process. Are the phonological processes that support visual word identification facilitated by repetition priming manipulations, or do repetition priming effects occur only at some other level of processing? Put another way, the issue we address is whether the effect of implicit memory on visual word identification includes a phonological component.

To preview what follows, the results of the experiments reported below show that repetition priming facilitates the phonological processes involved in reading. These results demonstrate that priming transfers across interpretations of a homophone. That is, seeing or hearing week primes both week and weak in a visual stem completion task. Because homophones are pronounced

This research was supported by Grant HD-01994 from the National Institute of Child Health and Development to Haskins Laboratories. Correspondence should be addressed to J. G. Rueckl, Department of Psychology, University of Connecticut, Storrs, CT 06269 (e-mail: rueckl@psych.psy.uconn.edu). identically but differ in both spelling and meaning, the transfer of priming between homophones strongly suggests that visual repetition priming includes a phonological component.

\section{Phonological Effects in Visual Word Identification}

The role of phonological processes in visual word identification has been the topic of much debate (see Carr \& Pollatsek, 1985, Humphreys \& Evett, 1985, and Van Orden, Pennington, \& Stone, 1990, for reviews). Although it was once widely held that phonological processes contribute relatively little to the identification of written words in most circumstances (Doctor \& Coltheart, 1980; Humphreys \& Evett, 1985; McCusker, Hillenger, \& Bias, 1981), a variety of recent findings have led many theorists to conclude that phonological processes play a much more important role in word identification than was once thought (e.g., Carello, Turvey, \& Lukatela, 1992; R. Frost, 1998; Perfetti \& Bell, 1991; Van Orden et al., 1990).

One such set of findings involves the effects of shortterm priming (see, e.g., Grainger \& Ferrand, 1994; Humphreys, Evett, \& Taylor, 1982; Lukatela \& Turvey, 1994b; Perfetti \& Bell, 1991). In the short-term priming paradigm, a target word is preceded by a prime at a relatively brief stimulus onset asynchrony (SOA), and the relationship between the prime and the target is manipulated. A variety of studies have found that the processing of a target word is facilitated by the presentation of a phonologically related prime. For example, masked target words are more accurately identified when preceded by a homophone prime (e.g., maid-made) than when preceded by orthographic control (e.g., mark-made; Humphreys et al., 1982). Pseudohomophonic primes (e.g., maydmade) also facilitate the identification of masked target 
words more than do orthographically matched nonpseudohomophones (e.g., mard-made; Perfetti \& Bell, 1991). Moreover, homophone and pseudohomophone priming have also been observed in the lexical decision task (Grainger \& Ferrand, 1994) and the naming task (Lukatela \& Turvey, 1994b). The key point here is that, given that the SOAs in these studies are typically on the order of 30-60 msec, homophone and pseudohomophone priming effects indicate that readers gain rapid access to a word's phonology.

Moreover, the computation to a phonological code is not only fast, but it is also results in the activation of information about the meaning(s) associated with that code. Thus, Lukatela and Turvey (1994a) found that a target word (e.g., frog) is primed not only by an associated word (e.g., toad), but also by a homophone (e.g., towed) or pseudohomophone (e.g., tode) of that associate. Similarly, Van Orden (1987) and others (e.g., Jared \& Seidenberg, 1991; Peter \& Turvey, 1994) have found that when participants make speeded judgments concerning whether a target word (e.g., rose) is a member of a prespecified category (e.g., flower), homophone foils (e.g., rows) and pseudohomophone foils (e.g., roze) give rise to more false-positive errors than do orthographically matched control foils (e.g., robs). Importantly, given that the costs associated with homophony would be eliminated if readers chose not to engage phonological processes, the fact that homophony does interfere with performance in these tasks strongly suggests that phonological processes are carried out automatically.

Results such as these provide strong support for the view that phonological processes play an important role in visual word identification. Effects associated with phonological processes are found in a variety of experimental paradigms, at extremely short time scales, and even when availability of a phonological code is associated with a decrement in performance. This being said, it should also be noted that in certain respects the jury is still out with regard to the role of phonology in reading. In particular, contemporary accounts of visual word identification differ in their assumptions concerning the time course of phonological and nonphonological processes and their relative importance in lexical access (cf. Coltheart, Curtis, Atkins, \& Haller, 1993; Lukatela \& Turvey, 1994a, 1994b; Plaut, McClelland, Seidenberg, \& Patterson, 1996; Seidenberg, 1992; Van Orden et al., 1990). Nonetheless, regardless of whether visual word identification necessarily results from phonological computations or whether it results from the cooperation of phonological and nonphonological processes, overwhelming evidence indicates that phonological processes play an early and important role in visual word identification. What interests us here is whether this understanding of the word identification process has any bearing on theoretical accounts of repetition priming.

\section{Phonological Effects in Repetition Priming}

It is conceivable that the processes that underlie repetition priming are only indirectly related to the phono- logical processes that subserve visual word identification. For example, Morton (1979) proposed that repetition priming is brought about by a change in the threshold of the logogen (i.e., representation of visual/orthographic form) that serves as a word's "access unit" in the identification process. Similarly, Schacter (1992) has argued that visual repetition priming reflects the operation of a presemantic visual word form system. Thus, both accounts assume that the primary locus of visual repetition priming involves modality-specific (and hence nonphonological) representations. Moreover, although this assumption does not necessarily preclude the possibility of a secondary phonological locus for priming effects, it is fair to say that neither account suggests that a phonological locus is to be expected.

In contrast, several other accounts of repetition priming do generate such an expectation. For example, transferappropriate processing accounts (Roediger, 1990; Roediger \& Blaxton, 1987; Weldon, 1991) hold that priming occurs to the degree that the processing of the prime and the processing of the target involve the same processes. Thus, these accounts imply that to the extent that phonological processes play an important role in the identification of a written word, repetition priming will include a phonological component. Connectionist models of repetition priming lead to a similar prediction. From a connectionist perspective, repetition priming reflects the influence of the learning process that modifies the strengths of the connections within the processing network responsible for word identification (McClelland \& Rumelhart, 1985; Rueckl, 1990; Rueckl \& Olds, 1993). Coupled with the assumption that the architecture of this network places phonological processes in a pivotal role in the identification process, this account predicts that the weight changes that underlie repetition priming will include a distinctly phonological component.

Thus, just as evidence concerning the role of phonology in reading places constraints on theories of word identification, so too can it inform accounts of implicit memory. Yet, perhaps surprisingly, relatively little research has focused on the role of phonology in repetition priming. It is worth noting, however, that the experimental findings that are relevant to this issue suggest that implicit memory effects on visual word identification tasks include a phonological component.

Consider, for example, the results of a series of experiments investigating the effects of rhyme priming on visual stem completion. During the study phase of these experiments, participants read either a list of words (Mandler, Graf, \& Kraft, 1986; Mandler, Hamson, \& Dorfman, 1990) or a poem (Overson \& Mandler, 1987) that contained words that rhymed with a target word, but not the target word itself. Relative to an unprimed baseline condition, rhyme priming both increased the likelihood that target words were generated during a subsequent stem completion task (Mandler et al., 1986; Mandler et al., 1990; Overson \& Mandler, 1987) and reduced the time needed to generate these completions (Mandler et al., 1990). Although the effect of rhyme priming ap- 
pears to be fairly short-lived relative to direct repetition priming (Mandler et al., 1986), the fact that it occurs at all suggests that implicit memory on visual test tasks includes a phonological component.

Masson and Freedman (1990, Experiment 6) also reported experimental evidence consistent with a phonological effect in visual implicit memory. During the study phase of their experiment, participants read aloud a series of words and pseudohomophones (e.g., krooze, rale). In a subsequent speeded naming task, words that had been presented during the study phase were named faster than words that were not on the study list. More importantly, naming latencies for the real-word counterparts of the pseudohomophones (e.g., cruise, rail) were also facilitated. One interpretation of the pseudohomophone priming effect is that it reflects the activation of the phonological code shared by a word and its pseudohomophone. However, an alternative explanation (favored by Masson \& Freedman) is that the processing of a pseudohomophone results in the activation of the meaning of its lexical counterpart, and that the locus of (longterm) pseudohomophone priming is at the semantic level. Thus, although the pseudohomophone priming effect is consistent with a phonological account, it is also open to other interpretations.

A similar sort of ambiguity arises in the literature on cross-modal priming. In the cross-modal paradigm, participants hear a series of auditorally presented words and then perform a visual task such as lexical decision or stem completion. Most studies of cross-modal priming have shown that changes in modality between study and test reduce, but do not eliminate, repetition priming (see Kirsner, Dunn, \& Standen, 1989, and Roediger \& McDermott, 1993, for reviews). Cross-modal priming could have a phonological basis (Kirsner et al., 1989). That is, if the phonological code that is activated when a word is heard is also accessed during a visual task involving that word, this could result in facilitation of the visual task. However, phonological processes are not the only possible source of cross-modal priming effects. For example, a number of authors have argued that cross-modal priming occurs because the spoken and written forms of a word activate the same semantic code (e.g., Bassili, Smith, \& MacLeod, 1989; Keane, Gabrieli, Fennema, Growden, \& Corkin, 1991; Masson \& Freedman, 1990). Alternatively, if hearing a word results in the activation of its orthographic code (S. J. Frost, Fowler, \& Rueckl, 1998; Jakimik, Cole, \& Rudnicky, 1985; Seidenberg \& Tanenhaus, 1979), the locus for both within- and betweenmodality priming may involve orthographic representations. Note that these accounts are not mutually exclusive: Repetition priming (whether within or across modalities) could involve any combination of orthographic, semantic, and phonological factors. Thus, because the activation of a word's phonological representation is usually correlated with the activation of its orthographic and semantic codes, demonstrating that phonological processes contribute to visual repetition priming represents something of an experimental challenge.

\section{Isolating the Phonological Component}

If the identification of a written word results in the parallel activation of orthographic, phonological, and semantic codes, how can the contribution of any particular code be isolated from the backdrop of the others? One possibility is to manipulate a variable that influences one level of processing while leaving the others relatively unaffected. For example, by manipulating the context in which a word appeared (thus changing its meaning but not its spelling or pronunciation), Masson and Freedman (1990) obtained results suggesting that repetition priming includes a semantic component. In particular, they found that repetition effects in the lexical decision task decreased when the context word that accompanied a repeated target was changed so that a different meaning was implied.

Because some words are phonologically ambiguous (e.g., heterophonic homographs such as read and lead), one might attempt to investigate the role of phonology in priming using a similar approach. Pragmatically, however, the small number of heterophonic homographs (at least in English) precludes the possibility of sufficiently powerful experimental designs. More importantly, because the alternative interpretations of a heterophonic homograph differ in both pronunciation and meaning, manipulations that change the interpretation of a homograph between study and test will not selectively influence phonological processes.

In the experiments reported below, we took a different tack. Rather than attempting to manipulate the phonological level while holding all other factors constant, we chose to hold phonology constant while changing everything else. One way this can be accomplished is by making use of heterographic homophones (e.g., week-weak). Because such homophones are both phonologically identical and different in spelling and meaning, they provide an excellent opportunity to investigate the role of phonology in visual repetition priming. More specifically, if hearing or seeing a word primes its homophone (e.g., if seeing week primes weak), the locus of this effect most likely involves phonological processes because this is the only code common to both words. Thus, a homophone priming effect would provide strong evidence that visual repetition priming includes a phonological component.

\section{EXPERIMENT 1}

On the assumption that the reduction in priming brought about by a change in modality is primarily related to visual/orthographic processes, the relative influence of the phonological component is likely to be greater in the cross-modal condition. Thus, in our initial experiments we chose to investigate the effects of homophone priming within the cross-modal paradigm. Note, 
however, that the decision to present the primes auditorally leads to a major experimental obstacle. Namely, our experimental logic demands that we control how each homophonic prime is interpreted, and although the interpretations of a homophone differ in spelling, they sound exactly alike.

Our solution was to use contextual information to disambiguate each homophone (a procedure somewhat akin to that of Masson \& Freedman, 1990). During the priming phase of Experiment 1, each critical homophone was presented in a context that biased its interpretation toward one or the other of its meanings. For example, the word /wik/ (i.e., the pronunciation of week and weak) was presented in one of two contexts: "Which state of health is most unlike the others: weak, strong, healthy, robust?" or "Which period of time is most unlike the others: decade, century, week, millennium?"

One member of each homophone pair was designated the target interpretation (e.g., for the weak-week pair, weak was the target), and the three-letter stem of each target (e.g., wea_ _ was presented during a stem completion task that followed the semantic judgment task. The relationship between the study and test items was manipulated. In the repeated condition, a homophone was presented in the context favoring the target interpretation (e.g., /wik/ was presented in the context biased toward weak). In the homophone condition, the context was biased toward the other interpretation (e.g., week). Finally, in the baseline condition the homophone was not presented during the study task.

Given this design, homophone priming would be revealed by a higher target completion rate in the homophone condition than in the baseline condition. Because the alternative interpretations of a homophone are phonologically identical and differ in both spelling and meaning, a significant homophone priming effect would provide compelling evidence that repetition priming on a visual task includes a phonological component.

\section{Method}

Participants. Thirty-six Harvard University undergraduate students were paid $\$ 3$ to $\$ 4$ for their participation. All participants were native speakers of English.

Design and Materials. The critical stimuli included a list of homophonic word pairs (e.g., weak-week). One member of each pair was designated the target word. The targets were chosen to satisfy several constraints. First, the three-letter stem of each target (e.g., wea_) was required to differ from that of its homophone (e.g., wee__. Thus, homophonic pairs such as threw-through were not used. Second, only words with stems that could be completed with at least three other words (c.g., wear, weave, weak, etc.) were included as targets. Third, the results of several pilot studies were used to select target words with baseline completion rates ranging from 0.04 to 0.50 .

The construction of the stimulus set was also constrained by the characteristics of the study task. Because the stimuli were presented auditorally during this task, it was essential that each homophone was presented in a context that steered the listeners toward the intended interpretation. Thus, during the study task the participants performed a semantic judgment task in which they were asked to identify which of four related concepts was least like the others. For example, for the homophonic pair weak-week, the participants were asked either, "Which state of health is most unlike the others: weak, strong, healthy, robust?" or "Which period of time is most unlike the others: decade, century, week, millennium?" These questions were constructed so that the "correct" answer was the target or its homophone. The results of a pilot study indicated that listeners consistently chose the homophone and that they interpreted the homophone as intended (i.e., they did not hear weak as week or vice versa).

In addition to these restrictions, a final restriction on the construction of the stimuli was that none of the alternatives presented during the semantic judgment task was a legal completion for any of the critical stems (with the exception, of course, of the target words). Together, the constraints related to the stem completion and semantic judgment tasks eliminated many possible homophonic word pairs. As a result, the critical stimuli for this experiment included 18 such pairs-a relatively small number for an experiment of this type. (The targets and homophone primes are listed in Appendix A.)

The main independent variable in this experiment was the relationship between a target word and the stimuli presented during the semantic judgment task. In the repeated condition, the target word was presented during the study task; that is, the participants heard the question requiring them to interpret the critical word as the target. In the homophone condition, the participants heard the question favoring the other interpretation. Finally, in the unprimed condition, neither the target nor its homophone was presented during the study task.

In order to counterbalance the stimuli across the priming conditions, the list of 18 critical word pairs was partitioned into three sublists of six pairs each. For each participant, one of the sublists was assigned to the repeated condition, a second sublist was assigned to the homophone condition, and the remaining sublist was assigned to the unprimed condition. With three such counterbalancing assignments, each sublist was assigned to each condition equally often across participants.

The questions for the semantic judgment task were spoken by an adult male and recorded on cassette tape. Three such tapes were recorded-one for each of the counterbalancing conditions. Each tape began with two filler questions, which were then followed by 12 critical questions ( 6 for the repeated condition and 6 for the homophone condition). These questions were presented in a random order and were followed by two more filler questions. The questions were read at a slow pace, with about a $1-\sec$ pause between each of the alternative responses. In addition, to ensure that the participants understood each question, the list of alternative responses was repeated after each question. There was a pause of about 4 sec between questions.

The stimuli for the stem completion task included the stems for the 18 target words and an additional 12 fillers. The stems were typed in 12-point New York font, and immediately to the right of each stem was an underlined space in which the participants wrote their responses. The stems were arranged in a random order in three columns on a single sheet of paper, with the restriction that the first four stems in the first column were fillers. Three different random orders were used.

Procedure. Participants were run individually in experimental sessions that lasted approximately $20 \mathrm{~min}$. Each session began with the semantic judgment task. The participants were told that the purpose of this task was to investigate "how people represent knowledge about categories" and that they should respond to each question by saying their answer aloud. The recording of the list of questions was played on a desktop cassette deck at a comfortable volume, and the participants' responses were recorded using a second cassette deck.

Following the semantic judgment task, a distractor task was administered. Each participant was given a list of fragmented famous 


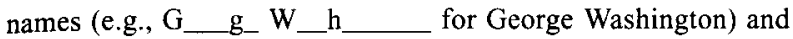
asked to complete as many of the fragments as possible. After 3 min, work on the famous names task was halted and the instructions for the stem completion task were given. These instructions noted that "sometimes you may notice that you complete a stem with a word from the earlier part of the experiment," but emphasized that the participant's task was to respond with "the very first word that comes to mind." The participants were told to work quickly, but were allowed to set their own pace.

\section{Results and Discussion}

Table 1 presents the proportion of target completions in each priming condition. As expected, the target completion rate was highest in the repeated condition and lowest in the unprimed condition. An analysis of variance revealed that the effect of priming condition was significant by participants $\left[F_{1}(2,70)=3.58, M S_{\mathrm{e}}=.122\right.$, $p<.05]$ and by items $\left[F_{1}(2,34)=6.47, M S_{\mathrm{e}}=.070, p<\right.$ $.005]$. A series of one-tailed $t$ tests revealed evidence of the predicted effects of repetition and homophone priming. More target completions were generated in the repeated condition than in the unprimed condition $\left[t_{1}(35)=\right.$ $\left.2.44, p<.01, t_{2}(17)=3.65, p<.001\right]$. Similarly, more target completions were generated in the homophone condition than in the unprimed condition. This difference was significant by items $\left[t_{2}(17)=2.26, p<.02\right]$ and marginally significant by participants $\left[t_{1}(35)=1.65, p<\right.$ $.06] .{ }^{1}$ Finally, the target completion rate was numerically larger in the repeated condition than in the homophone condition; however, this difference was only marginally significant in both analyses $\left[t_{1}(35)=1.25, p<.11\right.$, $\left.t_{2}(17)=1.55, p<.08\right]$.

Thus, the major finding of Experiment 1 is that priming transferred across interpretations of a homophone. Given that homophonic words are phonologically identical but differ in spelling and meaning, homophonic priming unambiguously reveals the role of phonological processes in visual repetition priming. Further, priming was numerically greater in the repeated condition than in the homophone condition. Although this difference only approached statistical significance, it is consistent with the possibility that semantic and/or orthographic processes also contribute to cross-modal priming.

\section{EXPERIMENT 2}

The results of Experiment 1 provide evidence that visual repetition priming includes a phonological component. However, certain aspects of the methodology of

Table 1

The Proportion of Target Completions in Experiments 1-4 as a Function of Priming Condition

\begin{tabular}{ccccc}
\hline & \multicolumn{4}{c}{ Priming Condition } \\
\cline { 2 - 5 } Experiment & Repeated & Homophone & Orthographic & Unprimed \\
\cline { 2 - 5 } 1 & .296 & .231 & - & .171 \\
2 & .268 & .202 & - & .146 \\
3 & .303 & .179 & - & .126 \\
4 & .295 & - & .114 & .117 \\
\hline
\end{tabular}

that experiment raise questions about the generality and implications of this finding. In particular, because both speech perception and speech production necessarily involve phonological processes, the priming task used in Experiment 1 (in which participants both heard the primes and spoke them aloud) may have been especially favorable for the occurrence of a phonologically based priming effect. Whether homophone priming would occur if the study task did not explicitly require the computation of phonological codes remains undetermined. In addition, it is possible (although perhaps unlikely) that hearing a homophone activates visual/orthographic representations of each of its interpretations. If so, the homophone priming effect observed in Experiment 1 would not be the signature of a phonological component of visual repetition priming.

The next experiment was designed to address both of these issues. This experiment again investigated the effects of homophone priming on visual stem completion. As in Experiment 1, the homophone primes were presented in the context of a semantic judgment task. However, the primes in Experiment 2 were presented visually, and participants indicated their responses manually (by circling the correct response). Thus, because the words presented during the priming task were neither heard nor spoken by the participants, the computation of a phonological code was not explicitly required in this version of the priming task. Moreover, given that the primes were presented visually, it seems unlikely that the visual/orthographic representations of other words (including any homophones of the prime) were activated to the degree required to produce long-term priming.

\section{Method}

Participants. Thirty-three University of Connecticut undergraduate students participated in exchange for course credit. All participants were native speakers of English.

Design and Procedure. The design of Experiment 2 was identical to that of Experiment 1 except that the stimuli in the study task were presented visually rather than auditorally. The stimulus materials were identical, and each participant performed the same series of tasks (i.e., semantic judgments, famous names, and then stem completion).

Several aspects of the procedure were modified to accommodate the change in the modality of the study task. The questions for the semantic judgment task were typed on two sheets of paper in the same order that they had been asked in Experiment 1 (and in the same font used for the stem completion task). The participants were instructed to read through the list of questions at their own pace and to indicate their response by circling the correct alternative. They were also told not to look back at their earlier responses and to turn over each page as soon as it was completed.

Experimental sessions were run with groups of 3-10 participants. When all of the participants in a group had completed the semantic judgment task, the experimenter administered, in turn, the famous names and stem completion tasks. The procedure for these tasks was identical to that of Experiment 1.

\section{Results and Discussion}

The results of Experiment 2 are presented in Table 1. As the table indicates, these results closely resemble those 
of Experiment 1. The target completion rate again varied as a function of priming condition $\left[F_{1}(2,64)=4.61, M S_{\mathrm{e}}=\right.$ $\left..120, p<.05 ; F_{2}(2,34)=6.71, M S_{\mathrm{e}}=.066, p<.005\right]$. More target completions were generated in the repeated condition $\left[t_{1}(32)=2.85, p<.005 ; t_{2}(17)=3.60, p<.005\right]$ and in the homophone condition $\left[t_{1}(32)=1.85, p<.05\right.$; $\left.t_{2}(17)=1.94, p<.05\right]$ than in the unprimed condition. Thus, performance in the stem completion task was influenced by both repetition and homophone priming. In addition, a target was more likely to be generated if it had been primed by itself rather than by its homophone. This difference was significant by items $\left[t_{2}(17)=1.79, p<\right.$ $.05]$ and marginally significant by participants $\left[t_{1}(32)=\right.$ $1.42, p<.09]$.

Thus, the results of this experiment replicate and extend those of Experiment 1. As in the first experiment, the probability that a target word was generated during the stem completion task increased if a homophone of that word had been encountered during the priming task. However, in the present case the primes were read rather than heard. Because it is unlikely that upon seeing a given prime our participants chose to activate an orthographic representation of that prime's homophone, it is reasonable to conclude that homophonic priming reflects the contribution of phonological representations that were activated during both the study and test tasks.

Finally, it is worth noting that a comparison of the results of Experiments 1 and 2 yields one somewhat surprising result. It has typically been found that a change in modality between study and test reduces the magnitude of identity priming by about half (Kirsner et al., 1989; Roediger \& McDermott, 1993). In contrast, in the present experiments cross-modal priming (Experiment 1) and within-modality priming (Experiment 2 ) yielded effects of approximately equal size. It is possible that this atypical pattern reflects the fact that responses during the semantic judgment task in Experiment 1 were spoken, whereas in Experiment 2 participants responded by simply circling the correct response. Alternatively, this pattern may reflect differences in how the study items were presented during each experiment. In Experiment 1, the pace of presentation was controlled by the experimenters, whereas in Experiment 2 participants responded at their own pace. Our impression is that the participants completed the study task more quickly (and probably with less effort) during the latter experiment.

\section{EXPERIMENT 3}

In Experiments 1 and 2, the primes were presented in the context of a semantic judgment task. One disadvantage of this task is that it was often difficult to develop acceptable semantic judgment questions for both members of a homophone pair. Thus, a number of potential stimuli were eliminated from the already small set of English heterographic homophones - a problem confounded by the constraints of the stem completion task (e.g., word pairs like threw and through could not be used because they share the same three-letter stem). As a result, the critical stimuli for Experiments 1 and 2 included a relatively small set of 18 homophone pairs.

In Experiment 3, the characteristics of the study task were changed so that a larger number of homophone pairs could be included as stimuli. The use of the semantic judgment task was motivated by the need to provide contextual information to ensure that each spoken homophone was interpreted as we intended. However, disambiguating information need not be provided when homophone primes are presented visually. Thus, during the study phase of Experiment 3, we asked participants to rate the familiarity of individually presented written words. By eliminating the constraints on stimulus selection arising from the semantic judgment task, we were able to increase the number of homophone pairs used as stimuli from 18 to 33 .

\section{Method}

Participants. Thirty-nine University of Connecticut undergraduate students participated in exchange for course credit. All participants were native speakers of English.

Design and Procedure. The design was similar to that of Experiment 2. The most important difference was the change in the study task. During the study phase of the present experiment, participants rated the frequency of individually presented words. Because the frequency rating task places fewer constraints on stimulus selection than does the semantic judgment task, we were able to include more homophone pairs in the stimulus materials. Thus, the critical stimuli were 33 homophone pairs, including 17 of the 18 pairs used in the previous experiments. (The 18 th pair was dropped because its target word was never generated during the stem completion tasks of Experiments 1 and 2). These items were partitioned into three sublists of 11 pairs each, and across participants the sublists were rotated through the priming conditions (i.e., repeated, homophone, unprimed) in the same manner as in the previous experiments.

Experimental sessions were conducted in a small classroom with groups of 3-10 participants per session. Each session began with the frequency rating task. During this task, a Macintosh computer and DataView projection system were used to display the stimuli on a projection screen at the front of the room. Each word was presented for $5 \mathrm{sec}$ with a $1-\mathrm{sec}$ interval between words. As each word was presented, the participants rated its frequency on a $1-5$ scale $(1=$ very infrequent, $5=$ very frequent $)$ and wrote their ratings on the appropriate line of a response sheet. In addition to the 22 critical items ( 11 each from the repeated and homophone conditions), 28 filler words were also presented. The critical items and fillers were interspersed and randomly ordered, with the constraint that the first and last five items were fillers.

Following the frequency rating task, each participant completed the famous names (distractor) and stem completion tasks. The inclusion of more homophone pairs in the stimulus materials for the present experiment necessitated a slight change in the materials for the stem completion task. In particular, the stimuli for this task included the 33 critical stems and 42 fillers. These stems were arranged in a random order in three columns on each of two sheets of paper, with the restriction that the first four stems in the first column of the first page were fillers. Three different random orders were used. In all other respects, the famous names and stem completion tasks were administered in the same manner as in the previous experiments. 


\section{Results}

The results of Experiment 3 were consistent with those of the previous experiments (see Table 1). As expected, the proportion of target completions varied as a function of priming condition $\left[F_{1}(2,76)=26.81, M S_{\mathrm{e}}=\right.$ $\left..327, p<.001 ; F_{2}(2,64)=23.14, M S_{\mathrm{e}}=.272, p<.001\right]$. Both repetition priming and homophone priming influenced the performance of the stem completion task. More target completions were generated in the repeated condition than in the unprimed condition $\left[t_{1}(38)=7.81\right.$, $\left.p<.001 ; t_{2}(32)=6.01, p<.001\right]$. Similarly, the target completion rate was higher in the homophone condition than in the unprimed condition $\left[t_{1}(38)=2.33, p<.025\right.$; $\left.t_{2}(32)=2.43, p<.025\right]$. Finally, the difference between the repeated and homophone conditions was also significant $\left[t_{1}(38)=4.34, p<.001 ; t_{2}(32)=4.39, p<.001\right]$.

The results of Experiment 3 thus provide additional support for the hypothesis that visual repetition priming includes a phonological component. In the present case, the homophone priming effect was found using a larger stimulus set and a different study task from those employed in Experiments 1 and 2.

\section{EXPERIMENT 4}

We have argued that homophone priming reflects the contribution of phonological processes to visual implicit memory. That is, because heterographic homophones are phonologically identical but differ in spelling and meaning, the transfer of priming across homophones must have a phonological locus. Note, however, that this line of reasoning ignores the fact that in alphabetic languages there is a strong correlation between orthography and phonology: Generally, words that look alike also sound alike. Thus, although heterographic homophones such as week and weak differ in spelling, they are orthographically similar. Moreover, in at least some circumstances the identification of a target can be facilitated by an orthographically related prime (Feustal, Shiffrin, \& Salasoo, 1983; Rueckl, 1990; Rueckl \& Olds, 1993; Whittlesea, 1987). Thus, it is at least conceivable that the homophone priming effect observed in Experiments 1-3 reflects the contribution of orthographic, rather than phonological, processes.

Experiment 4 was designed to determine whether orthographic similarity underlies homophone priming. Toward this end, each of the homophone primes from Experiment 3 was replaced by an orthographic control word so that the orthographic and homophone primes were matched in their orthographic overlap with the target. (For example, for the target words weak and beat, the orthographic controls were teak and belt.) Note that because of the correlation between orthography and phonology, the orthographic primes of Experiment 4 bear some phonological similarity to their targets. Thus, the two experiments differed in degree of similarity along these dimensions. Compared with the homophone primes of Experiment 3 , the orthographic primes were less similar to their targets phonologically, but were at least as similar orthographically.

\section{Method}

Participants. Thirty University of Connecticut under ${ }_{\mathcal{S}}$ raduate students participated in exchange for course credit. None of these students had participated in any of the previous experiments.

Design and Procedure. The design of the present experiment was similar to that of Experiment 3, with the exception that the homophone priming condition of the previous experiment was replaced with an orthographic control condition. The orthographic primes were selected so that, whenever possible, the orthographic and homophone primes differed from their targets in the same letter position(s). However, because it was not always possible to satisfy this criterion, the orthographic similarity of each prime-target pair was computed using a procedure first developed by Napps (1989; see also Rueckl, Mikolinski, Raveh, Miner, \& Mars, 1997), and the control words were chosen so that they were, on average, at least as similar to the targets as were the homophone primes. (Using the Napps procedure, the average orthographic overlap was .65 in the homophone condition and .71 in the orthographic control condition, where 1.0 represents complete overlap and 0.0 represents no letters in common.)

The selection of the control words was also constrained so that the homophone and orthographic control primes shared the same number of letters with their target word's three-letter stem, and so that, if possible, the orthographic control word did not rhyme with its target. (See Appendix B for a complete list of stimuli.) In all other respects, the design and materials of Experiment 4 were identical to those of Experiment 3. Similarly, the procedure of the present experiment was nearly identical to that of the previous one. The only difference was that in the present experiment the study items were presented on a computer screen (rather than via an overhead projection system), and thus participants were run in groups of no more than 3 .

\section{Results and Discussion}

The results of Experiment 4 are presented in Table 1. As in the previous experiments, the proportion of target completions varied as a function of priming condition $\left[F_{1}(2,58)=24.85, M S_{\mathrm{e}}=.321, p<.001 ; F_{2}(2,64)=24.40\right.$, $\left.M S_{\mathrm{e}}=.358, p<.001\right]$, and more target completions were generated in the repeated condition than in the unprimed condition $\left[t_{1}(29)=5.54, p<.001 ; t_{2}(32)=5.10, p<\right.$ .001 ]. Importantly, inspection of Table 1 shows that both the baseline completion rate and the magnitude of repetition priming were nearly identical in Experiments 3 and 4. Thus, differences in the composition of the stimulus materials (i.e., the inclusion of homophone primes or their orthographic controls) appear to have had little effect on these aspects of the results.

The purpose of Experiment 4 was to determine whether the homophone priming effect observed in Experiments 1-3 might be attributable to the orthographic similarity of homophonic words. As can be seen in Table 1, there was no hint of a priming effect based solely on orthographic similarity-the completion rates in the baseline and orthographic control conditions were far from significantly different $\left[t_{1}(29)=-.20\right.$, n.s.; $t_{2}(32)=-.15$, n.s. $]$. Moreover, in a cross-experiment comparison, the completion rate in the homophone priming condition of Experiment 3 was significantly higher than the completion rate 
in the orthographic priming condition of Experiment 4 $\left[t_{1}(67)=2.40, p<.05 ; t_{2}(32)=2.49, p<.05\right]$. This pattern of results suggests that homophone priming reflects the phonological, and not the orthographic, similarity of homophonic words.

As an aside, we note that although the results of Experiment 4 clearly resolve one issue, they raise another. In particular, given that several studies have demonstrated priming effects attributable to orthographic similarity, one might ask why we failed to observe even a hint of an orthographic effect in Experiment 4. We can only speculate on this point, but we think it is fair to say that similarity priming is a relatively weak effect that typically fails to reach significance (see, e.g., the reviews by Roediger \& McDermott, 1993, and Stolz \& Feldman, 1995), and thus is difficult to observe unless the experimental conditions are especially favorable. Given this, it is worth noting that the present experiment contrasts with those that have demonstrated similarity priming (e.g., Feustal et al., 1983; Rueckl, 1990; Rueckl \& Olds, 1993; Whittlesea, 1987) in several potentially important ways. First, in the present experiment each prime was presented exactly once, but a substantial similarity priming effect may require multiple presentations of an orthographically similar prime (or primes). Second, similarity priming might be most easily observed with test tasks that limit the quality of the perceptual input (e.g., tachistoscopic identification, Rueckl, 1990, or identification-in-noise, Feustal et al., 1983). In contrast, although the stimuli in the stem completion task are "degraded" in the sense that only the first three letters are presented, each test stem is itself easily identifiable. Thus, relative to identification tasks, the stem completion task may deemphasize those visual/orthographic processes that are most sensitive to similarity priming.

In any event, our speculations about why an orthographic priming effect was not found should not detract from the more important implication of Experiment 4 namely, that the locus of homophone priming is the phonological code shared by both members of a homophone pair.

\section{GENERAL DISCUSSION}

The goal of this study was to determine whether repetition priming on visual word identification tasks includes a phonological component. The results of the experiments reported here demonstrate that this is the case. In Experiment 1, a target word was more likely to be generated in a visual stem completion task if its homophone had been heard during an earlier study task. Similarly, in Experiments 2 and 3, target words were primed if their homophones had been seen recently. Because homophonic words are phonologically identical but differ in spelling and meaning, the most plausible account of homophone priming is that it reflects the influence of a phonological code that is shared by both members of a homophone pair.
As noted in the introduction, a growing body of empirical evidence suggests that phonological processes play an early and essential role in visual word identification. The present results add to this evidence. In particular, for homophone priming to occur, the appropriate phonological code must be activated during the study task. On virtually any account, phonological activation would be expected during the study phase of Experiment 1 , in which the primes were both heard and spoken by the participants. However, nothing in the study tasks of Experiments 2 and 3 necessitated the computation of phonological codes - the participants saw the primes and responded manually (by either circling a word or writing a digit). That phonological codes were activated under these circumstances speaks to the fundamental role of phonological processes in reading. It appears that such processes are routinely conducted in the course of visual word identification (Lukatela \& Turvey, 1994a, 1994b; Van Orden et al., 1990).

Given the emphasis on phonology in this study, it is important to note that our results do not rule out the possibility that repetition priming also involves nonphonological components. Indeed, given that in each of Experiments $1-3$ identity priming was stronger than homophone priming (albeit not always significantly), it seems likely that several factors contributed to the priming effects observed in this study. Previous research suggests several possibilities. First, there is widespread agreement that the effect of priming on the identification of a written word is subserved, at least in part, by a representation of the visual and/or orthographic properties of that word. A variety of evidence can be marshaled in support of this view, including, for example, the cross-modal priming results discussed in the introduction (see, e.g., reviews by Schacter, 1992, and Roediger \& McDermott, 1993).

Another potential source of repetition priming is at the level of word meaning. For example, it has sometimes been argued that the priming effects observed in crossmodal paradigms reflect the contribution of semantic processes in priming (e.g., Bassili et al., 1989; Keane et al., 1991 ; Masson \& Freedman, 1990). However, others have questioned this interpretation (e.g., Kirsner et al., 1989; Toth \& Reingold, 1996), and, as pointed out in the introduction, in most cross-modal studies the relative contributions of semantics and phonology cannot be teased apart. Stronger evidence in favor of a semantic component in repetition priming comes from studies in which priming was found to weaken when the meaning of a word changed between study and test (e.g., Masson \& Freedman, 1990; Simpson \& Kang, 1994; Weldon, 1991). Additional support for a semantic component comes from a study by Becker, Moscovitch, Behrmann, and Joordens (1997), who found that, under certain circumstances, priming between semantically related words (e.g., whale-shark) occurs over a lag of 20 or more intervening items.

With this in mind, it should be noted that the results of the Lukatela and Turvey (1994a) study reviewed in the 
introduction suggest an alternative account for our homophone priming results. Recall that in that study a visually presented word (e.g., towed) was found to prime an associate of its homophone (e.g., frog), indicating that seeing a word activates not only its own meaning, but also that of its homophone. Thus, if semantic processes contribute to repetition priming, it is possible that the locus of the homophone priming effect observed in Experiments 1-3 involves semantic, rather than phonological, processes. ${ }^{2}$ Although we cannot completely rule out this possibility, we have good reason to think that it is unlikely. First, homophonic associative priming is a short-lived effect-the activation of the meaning of a target word's homophone is apparently suppressed within $500 \mathrm{msec}$ (Fleming, 1993; Lesch \& Pollatsek, 1993; Lukatela \& Turvey, 1994a; cf. Seidenberg, Tanenhaus, Lieman, \& Bienkowsi, 1982; Swinney, 1979). Second, in at least some circumstances, the suppression of an inappropriate meaning has an inhibitory effect that lasts for at least several minutes (Simpson \& Kang, 1994). Given the short-lived nature of inappropriate semantic activation and the possibility that its suppression has inhibitory consequences, it seems rather unlikely that long-term homophone priming has a semantic basis. The more plausible interpretation is that homophone priming reflects the role of phonological processes in reading.

To summarize, then, our findings provide strong evidence that visual repetition priming includes a phonological component. Moreover, although we cannot conclusively determine whether priming also occurred at the level of word form and/or word meaning, our results, when coupled with other findings, are consistent with the view that the learning process that underlies repetition priming is not unique to any one level of representation. Instead, priming effects appear to be "smeared" throughout the processing system. That is, the outcome of a processing event reflects the contribution of many operations, each of which leaves a memory trace that will, under the appropriate conditions, influence subsequent behavior. In the case of visual word identification, these processes include the construction of orthographic, phonological, and semantic codes.

Put in these terms, it is clear that our interpretation of homophone priming is consistent with processing approaches to implicit memory (e.g., Roediger, 1990; Roediger \& Blaxton, 1987; Weldon, 1991). As Roediger (1990, p. 1049) stated, the central tenet of such theories is that "performance on memory tests benefits to the extent that the cognitive operations at test recapitulate (or overlap) those engaged during initial learning." It should be noted, however, that the general framework provided by the transfer-appropriate processing approach is neutral with regard to the role of phonological processes in repetition priming. Specific expectations concerning the role of phonology in priming can be derived only when the general principles supplied by this framework are coupled with specific assumptions derived from theo- retical accounts of the word identification process. Thus, the componential view of repetition priming described above represents a union of processing theories of memory with models that hold that word identification involves the parallel construction of orthographic, phonological, and semantic codes (see, e.g., Coltheart et al., 1993; Katz \& Feldman, 1983; Plaut et al., 1996; Seidenberg, 1992). We have argued elsewhere (Rueckl, 1990; Rueckl et al., 1997) that the connectionist framework provides a formalism with which this union can be developed.

Finally, it should be noted that although we have linked the componential view of repetition priming to processing theories of memory, it can also be seen as the joining of word identification models with the main alternative to processing theories - namely, the multiple memory systems approach (Schacter, 1992; Tulving \& Schacter, 1990). A key tenet of the systems approach is that learning and memory reflect the operation of a number of functionally and anatomically distinct memory subsystems. For example, in Schacter's (1992) formulation of the systems account, separate subsystems are responsible for the representation of visual word form, auditory word form (including, in part, phonological structure), and word meaning. It is noteworthy, then, that evidence that orthographic, phonological, and semantic processes are localized in different brain areas has played an important role in the development of models of word identification.

Thus, at a global level there are obvious parallels between the systems theory and multiple-code models of word identification. What is less obvious is the degree to which these approaches are congruent at finer levels of analysis. In particular, the componential nature of repetition priming effects suggests a high degree of interaction between processes at each level of representation. Such interactionism is also a feature of most multiplecode models of word identification. In contrast, although the systems approach does not explicitly rule out the possibility of interactive processes between subsystems, this possibility has received relatively little consideration in the development of systems accounts. Thus, what implications the incorporation of interactive processes would have for the systems framework remain unclear.

\section{REFERENCES}

Bassili, J. N., Smith, M. C., \& MacLeod, C. M. (1989). Auditory and visual word-stem completion: Separating data-driven and conceptually driven processes. Quarterly Journal of Experimental Psychology, 41A, 439-453.

BeCKer, S., Moscovitch, M., Behrmann, M., \& JoORdens, S. (1997). Long-term semantic priming: A computational account and empirical evidence. Journal of Experimental Psychology: Learning, Memory, \& Cognition, 23, 1059-1082.

Carello, C., Turvey, M. T., \& Lukatela, G. (1992). Can theories of word recognition remain stubbornly nonphonological? In R. Frost \& L. Katz (Eds.), Advances in psychology: Orthography, phonology, morphology, and meaning (pp. 45-66). Amsterdam: Elselvier, NorthHolland

Carr, T. H., \& Pollatsek, A. (1985). Recognizing printed words: A 
look at current models. In D. Besner, T. G. Waller, \& G. E. MacKinnon (Eds.), Reading research: Advances in theory and practice (Vol. 5). Orlando, FL: Academic Press.

Coltheart, M., Curtis, B., Atkins, P., \& Haller, M. (1993). Models of reading aloud: Dual-route and parallel-distributed-processing approaches. Psychological Review, 100, 589-608.

Doctor, E. A., \& ColthearT, M. (1980). Children's use of phonological encoding when reading for meaning. Memory \& Cognition, 8 , 195-209.

Feustal, T. C., Shiffrin, R. M., \& Salasoo, A. (1983). Episodic and lexical contributions to the repetition effect in word identification. Journal of Experimental Psychology: General, 112, 309-346.

FLEMING, K. K. (1993). Phonologically mediated priming in spoken and printed word recognition. Journal of Experimental Psychology: Learning, Memory, \& Cognition, 19, 272-284.

Frost, R. (1998). Towards a strong phonological theory of visual word recognition: True issues and false trails. Psychological Bulletin, 123, 71-99.

Frost, S. J., Fowler, C. A., \& RueckL, J. G. (1998). Bi-directional consistency: Effects of a common phonology to speech and reading. Manuscript submitted for publication.

Grainger, J., \& Ferrand, L. (1994). Phonology and orthography in visual word recognition: Effects of masked homophone primes. Journal of Memory \& Language, 33, 218-233.

HENDERSON, L. (1982). Orthography and word recognition in reading. New York: Academic Press.

Humphreys, G. W., \& EvETt, L. J. (1985), Are there independent lexical and nonlexical routes in word processing? An evaluation of the dual-route model of reading. Behavioral \& Brain Sciences, 8, 689740 .

Humphreys, G. W., EvetT, L. J., \& TAYLOR, D. E. (1982). Automatic phonological priming in visual word recognition. Memory \& Cognition, 10, 576-590.

JAKIMIK, J., Cole, R. A., \& RUdNickY, A. I. (1985). Sound and spelling in spoken word recognition. Journal of Memory \& Language, 24, $165-$ 178.

JARED, D., \& SEIDENBERG, M. S. (1991). Does word identification proceed from spelling to sound to meaning? Journal of Experimental Psychology: General, 120, 358-394.

KatZ, L., \& Feldman, L. B. (1983). Relation between pronunciation and recognition of printed words in deep and shallow orthographies. Journal of Experimental Psychology: Learning. Memory, \& Cognition, 9, 157-166.

Keane, M. M., Gabrieli, J. D. E., Fennema, A. C., Growdon, J. H., \& CoRKIN, S. (1991). Evidence for a dissociation between perceptual and conceptual priming in Alzheimer's disease. Behavioral Neuroscience, 105, 326-342.

Kirsner, K., Dunn, J., \& Standen, P. (1989). Domain-specific resources in word recognition. In S. Lewandowsky, J. C. Dunn, \& K. Kirsner (Eds.), Implicit memory: Theoretical issues (pp. 99-122). Hillsdale, NJ: Erlbaum.

Lesch, M. F., \& Pollatsek, A. (1993). Automatic access of semantic information by phonological codes in visual word recognition. Journal of Experimental Psychology: Learning, Memory, \& Cognition, 19, 285-294.

Lukatela, G., \& Turvey, M. T. (1994a). Visual access is initially phonological: 1 . Evidence from associative priming by words, homophones, and pseudohomophones. Journal of Experimental Psychology: General, 123, 107-128.

Lukatela, G., \& Turvey, M. T. (1994b). Visual access is initially phonological: 2. Evidence from phonological priming by homophones and pseudohomophones. Journal of Experimental Psychology: General, 123, 331-353.

Mandler, G., Graf, P., \& Kraft, D. (1986). Activation and elaboration effects in recognition and word priming. Quarterly Journal of Experimental Psychology, 38A, 645-662.

Mandler, G., Hamson, C. O., \& Dorfman, J. (1990). Tests of dual process theory: Word priming and recognition. Quarterly Journal of Experimental Psychology, 42A, 713-739.

MASSON, M. E., \& FrEedMAN, L. (1990). Fluent identification of re- peated words. Journal of Experimental Psychology: Learning, Memory, \& Cognition, 16, 355-373.

MCClelland, J. L., \& Rumel haRT, D. E. (1985). Distributed memory and the representation of general and specific knowledge. Journal of Experimental Psychology: General, 114, 159-188.

MCCuSKer, L. X., Hillenger, M. L., \& BiAs, R. G. (1981). Phonological recoding and reading. Psychological Bulletin, 89, 217-245.

Morton, J. (1979). Facilitation in word recognition: Experiments causing a change in the logogen model. In P. A. Kolers, M. E. Wrostal, \& H. Bouma (Eds.), Processing visible language I (pp. 259268). New York: Plenum.

NAPPS, S. E. (1989). Morphemic relationships in the lexicon: Are they distinct from semantic and formal relationships? Memory \& Cognition, 17, 729-739.

Overson, C., \& Mandler, G. (1987). Indirect word priming in connected and phonological contexts. Bulletin of the Psychonomic Society, 25, 229-232.

Perfetti, C. A., \& Bell, L. (1991). Phonemic activation during the first $40 \mathrm{~ms}$ of word identification: Evidence from backward masking and priming. Journal of Memory \& Language, 30, 473-485.

Peter, M., \& Turvey, M. T. (1994). Phonological codes are early sources of constraint in visual semantic categorization. Perception \& Psychophysics, 55, 497-504.

Plaut, D. C., McClelland, J. L., Seidenberg, M. S., \& PattersON, K. (1996). Understanding normal and impaired word reading: Computational principles in quasi-regular domains. Psychological Review, 103, 56-115.

ROEDIGER, H. L., III (1990). Implicit memory: Retention without awareness. American Psychologist, 45, 1043-1056.

Roediger, H. L., III, \& BLAXTON, T. A. (1987). Retrieval modes produce dissociations in memory for surface information. In D. S. Gorfein \& R. R. Hoffman (Eds.), Memory and cognitive processes: The Ebbinghaus Centennial Conference (pp. 349-379). Hillsdale, NJ: Erlbaum.

ROEDIGER, H. L. III, \& MCDERMotT, K. B. (1993). Implicit memory in normal human subjects. In H. Spinnler \& F. Boller (Eds.), Handbook of neuropsychology (Vol. 8, pp. 63-130). Amsterdam: Elsevier.

RuECKL, J. G. (1990). Similarity effects in word and pseudoword repetition priming. Journal of Experimental Psychology: Learning, Memory, \& Cognition, 16, 374-391.

Rueckl, J. G., Mikolinski, M., Raveh, M., Miner, C., \& Mars, F. (1997). Morphological priming, fragment completion, and connectionist networks. Journal of Memory \& Language, 36, 382-405.

RueckL, J. G., \& OLDS, E. M. (1993). When pseudowords acquire meaning: The effect of semantic associations on pseudoword repetition priming. Journal of Experimental Psychology: Learning. Memory, \& Cognition, 3, 515-527.

SCHACTER, D. L. (1992). Priming and multiple memory systems: Perceptual mechanisms of implicit memory. Journal of Cognitive Neuroscience, 4, 244-256.

SEIDENBERG, M. S. (1992). Beyond orthographic depth in reading: Equitable division of labor. In R. Frost \& L. Katz (Eds.), Advances in psychology: Orthography, phonology, morphology, and meaning. (pp. 85-116). Amsterdarn: Elselvier, North-Holland.

Seidenderg, M. S., \& Tanenhaus, M. K. (1979). Orthographic effects on rhyme monitoring. Journal of Experimental Psychology: Human Learning \& Memory, 5, 546-554.

Seidenberg, M. S., Tanenhaus, M. K., Leiman, J. M., \& BienkowSKI, M. (1982). Automatic access of the meanings of ambiguous words in context: Some limitations of knowledge-based processing. Cognitive Psychology, 14, 489-537.

Simpson, G. B., \& KANG, H. (1994). Inhibitory processes in the recognition of homograph meanings. In D. Dagenbach \& T. H. Carr (Eds.), Inhibitory processes in attention, memory, and language (pp. 359381). New York: Academic Press.

Stolz, J. A., \& Feldman, L. B. (1995). The role of orthographic and semantic transparency of the base morpheme in morphological processing. In L. B. Feldman (Ed.), Morphological aspects of language processing (pp. 109-129). Hillsdale, NJ: Erlbaum.

SWINNEY, D. A. (1979). Lexical access during sentence comprehen- 
sion: (Re)Consideration of context effects. Journal of Verbal Learning \& Verbal Behavior, 18, 645-659.

ToTh, J. P., \& ReINGOLD, E. M. (1996). Beyond perception: Conceptual contributions to unconscious influences of memory. In G. Underwood (Ed.), Implicit cognition (pp. 41-84). Oxford: Oxford University Press.

Tulving, E., \& Schacter, D. L. (1990). Priming and human memory systems. Science, 247, 301-306.

VAN ORDEN, G. C. (1987). A ROWS is a ROSE: Spelling, sound, and reading. Memory \& Cognition, 15, 181-198.

Van Orden, G. C., Pennington, B. F., \& Stone, G. O. (1990). Word identification in reading and the promise of subsymbolic psycholinguistics. Psychological Review, 97, 488-522.

WELDON, M. S. (1991). Mechanisms underlying priming on perceptual tasks. Journal of Experimental Psychology: Learning, Memory, \& Cognition, 17, 526-541.

WhitTlesea, B. W. (1987). Preservation of specific experiences in the representation of general knowledge. Journal of Experimental Psychology: Learning, Memory, \& Cognition, 13, 3-17.

\section{NOTES}

1. Given the small number of items, it may seem surprising that the items analysis was more sensitive than the participants analysis. However, this outcome is sensible when one considers the manner in which the items were counterbalanced across conditions. In particular, the items were partitioned into three sublists that were rotated across the repeated, homophone, and baseline conditions across participants. Given this small numnber of items, the baseline values for the three sublists varied somewhat, and this variability adds noise to the participants analysis that is not present in the items analysis.

2. We thank Neil Mulligan for pointing this out.

\section{APPENDIX A \\ The Stimuli Used in Experiments 1 and 2}

The first member of each triplet is the target word; the second word is the homophone prime.

bear, bare; bury, berry; cellar, seller; cereal, serial; deer, dear; feat, feet; hole, whole; leek, leak; loan, lone; maid, made; meat, meet; pane, pain; rain, reign; seem, seam; suite, sweet; vein, vain; weak, week; weight, wait.

\section{APPENDIX B \\ The Stimuli Used in Experiments 3 and 4}

The first member of each triplet is the target word; the second word is the homophone prime (Experiment 3 ); the third word is the orthographic control prime (Experiment 4).

beat, beet, belt; bore, boar, bone; break, brake, freak; bury, berry, busy; cellar, seller, collar; cent, sent, went; cereal, serial, herbal; chute, shoot, acute; deer, dear, doer; fare, fair, fade; feat, feet, felt; hair, hare, harp; heal, heel, hell; here, hear, were; hole, whole, hose; leek, leak, meek; loan, lone, long; maid, made, said; mall, maul, mill; meat, meet, melt; pane, pain, pawn; peace, piece, place; rain, reign, ruin; real, reel, deal; right, write, rivet; sale, sail, sole; seem, seam, stem; soar, sore, star; suite, sweet, skate; vein, vain, venom; weak, week, teak; weight, wait, west; which, witch, watch.

(Manuseript received November 25, 1996; revision accepted for publication July 5,1997 . 